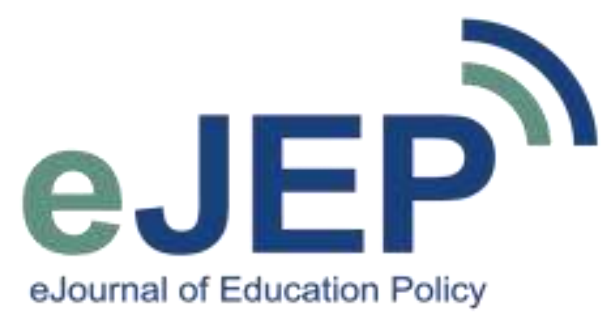

\title{
An Ethical Perspective on Increasing LGBTQIA+ Inclusivity in Education
}

To cite this article: Kuehn, H.C. (2020). An Ethical Perspective on Increasing LGBTQIA+ Inclusivity in Education. eJournal of Education Policy, 21(1).

https://doi.org/10.37803/ejepS2012

Heidi C. Kuehn

Part-time Faculty, Educational Leadership

Northern Arizona University

801 S. Knoles Dr.

Flagstaff, AZ 86011

heidi.kuehn@nau.edu

\begin{abstract}
All students should feel safe and included in educational contexts. Mission and values statements typically reflect this sentiment, but national, state, and local surveys indicate that some student groups continue to experience marginalization. Through these surveys, LGBTQIA+ students report that they perceive the school environment to be hostile. They do not experience equitable access to education. In recognition of this inequity, one public high school district in California initiated a task force to develop greater inclusivity in its schools. This paper analyzes their efforts from an ethical perspective and a focus on leadership.
\end{abstract}

Keywords: LGBTQ, LGBTQIA+, Inclusivity, Ethics, Leadership, Education

\section{Introduction}

Every student deserves to feel welcome and safe in the educational environment. This belief is commonly reflected in schools' mission and values statements, which express commitment to creating inclusive, equitable, and welcoming environments for all students. Slate et al. (2008) identified fifteen themes typically found in schools' mission statements, ten of these broadly having to do with the socioemotional well-being of students. Nurturing productive citizens with a high moral character who collaborate and partner respectfully with others is the essence of these statements, indicating that schools value more than just academic success and rigor.

Purposeful and well-written mission statements are linked with positive educational outcomes in higher education (Kuh et al., 2005). Because they reflect both the quality and the values of the insitution, they should inform policy, local decision-making, and broader organizational change. Kuh et al. advocated for a collaborative approach in creating mission statements to maximize buy-in and familiarity for all stakeholders in education. Despite the widespread use of mission statements in educational contexts, some student groups continue to experience marginalization. 
These groups include demographic descriptors such as race/ethnicity, socioeconomic status, gender, gender identity, sexual orientation, and dis/ability.

In the following pages, I will begin by discussing the important role of ethics in educational decision-making. Next, I will describe the educational experiences LGBTQIA+ (lesbian, gay, bisexual, transgender, queer or questioning, intersex, ally or asexual, and others) students as reported in local, state, and national surveys. Following this description, I will explain how a public high school district in California recognized that it had a problem and decided to respond.

\section{The Ethic of Critique}

If ethics is the study of right and wrong, then this subject is and should remain central in all educational settings. Even within a secular environment without religious context, educators are expected to teach and behave with morality, and the institution is similarly tasked with establishing and maintaining an atmosphere that reflects agreed-upon social norms and values.

The ethic of critique exposes the inequity of marginalization by redefining and reframing "other concepts such as privilege, power, culture, language, and even justice" (Shapiro \& Stefkovich, 2016, p. 14). Simply stated, it is unethical to allow some groups a place at the table while denying other groups the same level of access. Leaders in education who are guided by a strong sense of ethics do not consider it acceptable to allow policies and practices to perpetuate inequities. They disrupt the status quo by challenging such policies and working towards greater inclusivity. These are the leaders who take risks by pointing out flaws and challenging those who resist acknowledging the necessity of change. These are the educators who prioritize democratic values over self-interest. These are the people who advocate for the well-being of all students.

Critical theory informs the ethic of critique by helping educators recognize policies which benefit the majority group to the detriment of those who have been historically marginalized (Shapiro \& Stefkovich, 2016). "By demystifying and questioning what is happening in society and in schools, critical theorists may help educators rectify wrongs while identifying key morals and values" (p. 15). Paolo Freire's Pedagogy of the Oppressed is a classic example of critical theory in education. Freire (2000) explained that increasing equitable access to education empowers students. From a critical standpoint, education can help equalize the distribution of power in society. Inclusive education counteracts systemic marginalization.

\section{The Ethic of Care}

Shapiro and Stefkovich (2016) advocated "turning to the ethic of care for moral decision making" (p. 16). It is not enough to simply recognize a problem from a critical perspective; educators must use their internal ethical compass to drive decisions and initiate change. Infusing educational policies with greater inclusivity is only possible when policy-makers begin with the institution's mission statement, which is a public declaration of commitment to shared values. When new policies align with these values, it sends a message of cohesion and purpose to all stakeholders of the organization.

Organizational change is often accompanied by resistance from those who benefit from the status-quo (Kotter \& Cohen, 2002). Put simply, some teachers may prefer to continue doing 
things a certain way because it is easier not to have to develop new lessons and implement changes to existing policies and practices. To give a concrete example, students who identify as LGBTQ report higher levels of school engagement when they are exposed to an inclusive curriculum (Kosciw et al., 2018). Teachers may resist implementing such a curriculum for a variety of reasons. They may feel unqualified to do so, or they may fear the increased workload and potential push-back from students and parents. Educational leaders, interested in embracing inclusive policies, can dissolve this resistance more easily by revisiting agreed-upon values such as caring for all students' well-being. Once teachers realize that they can demonstrate care for their LGBTQ students by embracing an inclusive curriculum, they are more likely to welcome rather than resist change.

Noddings (1995) explained that the ethic of care is a central component of moral education. Some leaders in education may advocate for critical thinking in making difficult decisions, avoiding interference from emotions and feelings. Noddings suggested reconciling the two by concluding that "critical thinking guided by an ethic of care encourages us to stay in touch with our own feelings" (p. 195). From this perspective, the ethics of critique and care can function as complementary forces in guiding educational policy-makers. According to Shapiro and Stefkovich (2016), a strong ethical foundation paves the way for creating a more collaborative decision-making model in education.

Educational contexts rely on leaders to make difficult moral decisions guided by a strong sense of ethics. If this is true, "then there is a need to revise how educational leaders are prepared" (Shapiro \& Stefkovich, 2016). Instead of relying on models based on successful leadership in the world of business, the ethical paradigm requires leaders to incorporate a variety of perspectives and diverse voices. In the paragraphs that follow, I will outline how educational leaders in a public high school district in California applied the ethics of care and critique and the organization's common values to create and implement a task force to encourage and support greater LGBTQIA+ inclusivitiy.

\section{LGBTQIA+ Youth in the United States}

National surveys have indicated that LGBTQIA+ youth struggle in the school environment. The Youth Survey Report conducted by the Human Rights Campaign (HRC) found that over half of LGBT youth experienced verbal harassment in the school environment, which is twice as high as the general population (HRC, 2012). According to the most recent National School Climate Survey (NSCS), almost 60\% of all LGBTQ students represented felt unsafe at school due to their sexual orientation. Although almost all LGBTQ students heard homophobic comments at school, only $55.3 \%$ of these students reported these to school staff. This was because they did not think that anything would be done. Over $60 \%$ of those who did report discrimination indicated that they were told to ignore the harassment. LGBTQ students are more likely to skip school, and therefore less likely to graduate and pursue higher education (Kosciw et al., 2018).

The CDC's Youth Risk Behavior Survey (YRBS) reported that sexual minority youth are more likely to experience violence, engage in substance abuse, and participate in sexual behaviors deemed to be risky. They were also more likely to experience mental health issues, and $17.2 \%$ reported that they had seriously considered suicide (CDC, 2019). From a critical perspective, LGBTQIA+ students appear to perceive the school environment as hostile and this likely 
contributes to a lower sense of emotional well-being. Because educators care about all students, change is needed.

\section{California Healthy Kids Survey}

Only twenty years ago, little was known about the LGBTQIA+ student demographic (Kosciw et al., 2018). The only data available came from voluntary studies such as the NSCS and the YRBS, each with relatively small sample sizes compared to the population of students in United States public schools. It is difficult to advocate for greater inclusivity in the absence of strong statistical data. Failing to advocate for marginalized groups may send the message that the education system does not care about this demographic.

Recent legislation may help address some of the disparities in educational research. In February 2018, Assembly Bill 677 was signed into law by Governor Jerry Brown. This law requires public instutions in California to collect SOGI (sexual orientation and gender identity) data in voluntary and anonymous contexts. The same year, just over 40 school districts participated in the California Healthy Kids Survey (CHKS). Of the approximately 15,000 students participating, $75-87 \%$ of students in grades 7,9 , and 11 reported that they identified as heterosexual. Just under $10 \%$ reported that they were gay, lesbian, or bisexual, and around $1 \%$ identified as transgender. The data collected through the CHKS allows educators to study the LGBTQIA+ student population more accurately and determine how to better serve their needs.

In 2018-2019, the public high school district "Playa Vista" in Southern California surveyed $9^{\text {th }}$ and $11^{\text {th }}$ graders. Playa Vista concluded that the findings were largely consistent with the statewide results. Over 10\% of its students identified as LGBTQ (Austin, Polik, Hanson, \& Zheng, 2018). Between 20 and $40 \%$ of students reported that they heard homophobic and other negative comments about LGBTQ individuals "sometimes or often." Just under 10\% reported that they experienced harassment for these reasons. Up to $30 \%$ of the students felt that the school is not safe for students who do not behave or appear the way mainstream society defines as masculine or feminine.

Playa Vista's CHKS data mirrored NSCS results in that only about 30-40\% of students reported LGBTQ victimization when they witnessed it. Teachers attempted to help or solve a problem only $40 \%$ of the time when it was reported. Students reported that they were more likely to receive help from peers than from adults. Ten percent indicated that they heard negative comments from teachers and staff either "sometimes or often." Only about half of the students reported that they knew where to access help with LGBTQ issues, and many were not aware that the district had policies in place against discrimination and harassment on the basis of sex, sexual orientation, and gender. The majority of students answered that they were not convinced that adults at the school valued fairness and diversity. State-wide CHKS data were similar; about $20 \%$ of students reported that teachers do not treat students fairly or with respect. Educators at Playa Vista concluded that something needed to change.

\section{Playa Vista's Inclusivity Task Force}

In 2018, the Gay Straight Alliance (GSA, also known as Gender and Sexuality Alliance) at two of Playa Vista's high schools reviewed the CHKS data and expressed concern to district administration. When presented with the survey data from the CHKS, NSCS and YRBS, Playa 
Vista's superintendent "Dr. Peña" agreed to create and implement a task force aimed at providing a more inclusive educational environment for its students and professional development programs for the district's teaching staff. Dr. Peña was known for her commitment to students' emotional well-being, and her efforts to amend existing board policies regulating the district's graduation ceremonies had been successful.

According to Michael Fullan (2001), leadership is key during periods of intense emotions which can arise from change. Leaders can help all stakeholders adjust to new cultural norms in terms of LGBTQIA+ issues by providing needed support. This reflects adaptive leadership theory presented in Northouse (2016). Leaders profit from a wide perspective because they can understand and perceive the emotions around them. Through intentional communication and active listening, they can help individuals and groups feel better and able to cope with change. According to Burke (2018), an understanding of transformational leadership is helpful because it allows leaders to identify and counteract resistance from a variety of sources. Dr. Peña applied elements from both adaptive and transformational leadership theory in assisting all stakeholders of Playa Vista embrace the changes that the task force would promote.

A small group of volunteers attended a planning session in Dr. Peña's office in early January 2019. This planning committee decided to meet monthly to plan the larger task force meeting open to all district stakeholders. Dr. Peña invited all those interested, offering compensation at the contracted hourly rate. In mid-January, the first inclusivity task force met at the district office. Each school site was represented. Facilitators established norms, expressing commitment to establish an inclusive, safe space for all participants. After engaging in community-building exercises, the group outlined its goals for the remainder of the school year. Facilitators from the planning committee encouraged a collaborative approach in establishing the agenda for future meetings.

In February, the task force organized a LGBTQIA+ student panel who volunteered to participate in district-wide professional development slated for the following month. The panel of current and former Playa Vista Students was made available as an optional session for all teachers and administrators. It was well-attended, and participants interacted with LGBTQIA+ students and graduates who spoke about their experiences with discrimination and harassment in the school environment. There was every indication that Playa Vista teachers were open to hearing about students' perspectives and interested in learning about how to serve their socioemotional needs more effectively.

In April, shortly after the professional development program, Playa Vista's task force decided to ensure that all schools had a vibrant and active GSA. This was because GSA advisers brought research studies which demonstrate that LGBTQIA+ students benefit from a sense of community and school connectedness (Diaz, Kosciw and Greytak, 2010; Kosciw et al., 2018). Task force participants questioned why some district schools' GSA advisers had not committed to attending the monthly meetings, and agreed to reach out to their peers directly, inviting them to future meetings. By April, attendance at the task force meetings was noticeably reduced, but regular participants indicated a desire to promote the committee during the next school year. 
In May, members from the task force planning group created a virtual space on the district's learning management system. This would be an online toolkit where educators could find informational videos, pedagogical strategies, and lists of terminology and resources. Planning committee members suggested that representatives from each school site present the online toolkit at their last remaining faculty meeting in June. Some participants indicated a lack of confidence about the new technology. The task force decided to present the toolkit to a districtwide meeting of department chairs instead.

\section{Discussion}

Efforts to initiate systemic change are often met with complacency, immobility, or outright resistance (Kotter \& Cohen, 2002). In addition, schools tend to be bastions of (false) positivity, and stakeholders of these institutions may disbelieve that a problem even exists, especially when they do not identify with the marginalized demographic. In the case of Playa Vista, leadership indicated a willingness to create and encourage systemic change by implementing the inclusivity task force. Teachers demonstrated that they wanted to participate in the task force by attending monthly meetings and participating in the student panel discussion with obvious emotional engagement.

After a few months, attendance at the monthly task force meetings had dropped off. Although the group had collaboratively established goals, buy-in appeared to fade when members were asked to take on a leadership role at their individual school-sites. According to Kotter and Cohen (2002), successful organizational change depends on reliable buy-in. Bringing in those that may resist initial change efforts can increase the efficacy of the change process (Burke, 2018). In the case of Playa Vista, teachers and administrators communicated their intention to creating greater inclusivity and openly displayed a high level of caring for students who had experienced marginalization. This did not, however, predictably translate to representatives who were willing to communicate the task force's goals and objectives to their peers at individual school sites. This was complicated by impacted school and district calendars. End of school year procedures such as standardized testing and graduation took center stage in April and May, leaving little time to develop systematic training for how to use the online toolkit. It appeared that there were emotional as well as logistical barriers to implementing successful systemic change by the end of the school year.

\section{Limitations}

The relatively small sample size of the national, state, and local surveys described in this study present a clear limitation. Educational research must continue to expand to ensure accurate and reflective data. Only one school district is described as creating an inclusivity task force, and the discussion of their effort is limited to this single case. In addition, this study portrayed only the first few months of Playa Vista's inclusivity task force; there is much room for improvement, not only with respect to the continued growth of the district's task force, but also with respect to an expanded study with more generalizable findings.

\section{Future Research}

There is much room for growth in terms of future research. An increased sample size would lend depth to this study and reflect a wider variety of schools and school districts. Longitudinal studies about the efficacy of the inclusivity task force would likely yield useful information and 
could possibly incorporate comparisons of a variety of schools and school districts. Studies such as these could take on components of both qualitative and quantitative methods. Conducting research with a narrative study design and methodology may lead to greater depth of understanding. It would be valuable to interview teachers about their perspectives. How do they feel about inclusive policies and practices? What types of supports do they perceive that they need? Similarly, it would be helpful to query students about their viewpoints and experiences, and could possibly begin with the students of this same school district.

\section{Concluding Remarks}

This has been a dynamic decade in terms of LGBTQIA+ awareness. Increasing visibility in popculture and the media brings some issues to the forefront, and school climates reflect these changes. Moving towards greater inclusivity in the educational environment is not a task that is easily accomplished, nor is it likely to be effective without buy-in and involvement from a wide array of stakeholders. School mission statements are a good starting point, because individuals are more likely to embrace change when it reflects shared values, in this case a commitment to demonstrate caring for all students. 


\section{References}

Arriaga, T.T. \& Lindsey R.B. (2016) Opening doors: An implementation template for cultural proficiency. Corwin Press.

Austin, G., Polik, J., Hanson, T., \& Zheng, C. (2018). School climate, substance use, and student well-being in California, 2015-17. Results of the Sixteenth Biennial Statewide Student Survey, Grades 7, 9, and 11. WestEd.

Burke, W. (2018). Organization change : Theory and practice (Foundations for organizational science). SAGE Publications.

Center for Disease Control (2019). Youth risk behavior survey: Data summary and trends report, 2007-2017. https://www.cdc.gov/healthyyouth/data/yrbs/pdf/trendsreport.pdf

Diaz, E. M., Kosciw, J. G., \& Greytak, E. A. (2010). School Connectedness for Lesbian, Gay, Bisexual, and Transgender Youth: In-School Victimization and Institutional Supports. Prevention Researcher, 17(3), 15-17. https://go.gale.com/ps/anonymous?id=GALE\%7CA259750107\&sid=googleScholar\&v= $2.1 \& \mathrm{it}=\mathrm{r} \&$ linkaccess $=\mathrm{abs} \& \mathrm{issn}=10864385 \& \mathrm{p}=\mathrm{AONE} \& \mathrm{sw}=\mathrm{w}$

Freire, P. (2000). Pedagogy of the oppressed (30th anniversary ed.). Continuum.

Fullan, M. (2001). Leading in a culture of change (1st ed., Professional development collection). Jossey-Bass.

James, S. E., Herman, J. L., Rankin, S., Keisling, M., Mottet, L., \& Ana , M. (2016). The Report of the 2015 U.S. Transgender Survey. National Center for Transgender Equality.

Kosciw, J. G., Greytak, E. A., Zongrone, A. D., Clark, C. M., \& Truong, N. L. (2018). The 2017 National School Climate Survey: The experiences of lesbian, gay, bisexual, transgender, and queer youth in our nation's schools. GLSEN.

Kotter, J., \& Cohen, D. (2002). The heart of change : Real-life stories of how people change their organizations. Harvard Business School Press.

Kuh, G. D., Kinzie, J., Schuh, J. H., Whitt, E. J., \& Associates. (2005). Student success in college: Creating conditions that matter. San Francisco: Jossey-Bass.

Noddings, N. (1995). Philosophy of education (Dimensions of philosophy series). Westview Press.

Northouse, P. G. (2016). Leadership: Theory and practice (7th ed.). SAGE Publications, Inc.

Shapiro, J. P. \& Stefkovitch, J. A. (2011) Ethical Leadership and Decision Making: Applying theoretical perspectives to complex dilemmas, $3^{\text {rd }}$ ed. Routledge. 
Slate, J. R., Jones, C. H., Wiesman, K., Alexander, J., \& Saenz, T. (2008). School Mission Statements and School Performance: A Mixed Research Investigation. New Horizons in Education, 56(2), 17-27. 